\title{
HUBUNGAN UMUR DAN JENIS KELAMIN TERHADAP MYOFASCIAL TRIGGER POINT SYNDROME (MTPS)PADA GURU SMP AR RAHMAN
}

\author{
Ika Rahman \\ Jurusan DIII Fisioterapi, Politeknik Piksi Ganesha \\ Email: ikarahman@ politeknikpiksiganesha.ac.id
}

\begin{abstract}
Abstrak
Umur dan jenis kelamin seseorang akan berkaitan pada kapasitas fisik sampaibatas tertentu. Semakin bertambahnya umur seseorang maka kekuatan otot, kemampuan sensoris dan motoris juga akan menurun. Dengan demikian umur akan berhubungan terhadap pekerjaan terhadap seseorang. Secara umum wanita hanya mempunyai kekuatan fisik 2/3 dari kemampuan fisik atau kekuatan otot laki-laki, tetapi dalam hal tertentu wanita lebih teliti dari lakilaki.Untuk mendapatkan daya kerja yang tinggi, maka harus diusahakan pembagian tugas antara pria dan wanita sesuai dengan kemampuan, kebolehan dan keterbatasan masing-masing.Keluhan MTPS sering terjadi pada pekerja guru yang berhubungan dengan umur, sehingga mengakibatkan keluhan nyeri pada otot.Penelitian ini bertujuan untuk mengetahui hubungan Umur dan Jenis Kelamin terhadap Myofascial Trigger Point Syndrome (MTPS) terhadap guru di Sekolah Ar Rahman Medan.Jenis penelitian menggunakan desain analitik dengan rancangan cross sectional. Populasi dan sampel sebanyak 32 orang. Hasil penelitian bahwa terdapat hubungan umur $p$ value= $<0,005)$ dan tidak adanya hubungan jenis kelamin $(p$ value $=>0,05)$ terhadap Myofascial Trigger Point Syndrome (MTPS). Disarankan kepada guru untuk memanfaatkan waktu istirahat agar melakukan relaksasi otot agar dapat memperbaiki dan meningkatkan fungsi fisiologis.
\end{abstract}

Kata Kunci: Myofascial Trigger Point Syndrome (MTPS), Nyeri, Umur,Jenis Kelamin, Guru

\begin{abstract}
A person's age and gender will be related to physical capacity to some extent. As a person ages, muscle strength, sensory and motor abilities will also decrease. Thus age will be related to the work of a person. In general, women only have physical strength 2/3 of the physical ability or muscle strength of men, but in certain cases women are more careful than men. To get high work power, it is necessary to try to divide the tasks between men and women according to their respective abilities, skill and limitations. MTPS complaints often occur in teacher workers related to age, resulting in complaints of muscle pain. This study aims to determine the relationship between Age and Gender with Myofascial Trigger Point Syndrome (MTPS) against teachers at Ar Rahman School Medan. This type of research uses an analytic design with a cross sectional design. The population and sample were 32 people. The results showed that there was a relationship between age $(p$ value $=<0.005)$ and there was no relationship between sex ( $p$ value $=>0.05$ ) with Myofascial Trigger Point Syndrome (MTPS). It is recommended for teachers to take advantage of the rest time to relax muscles in order to improve and improve physiological function.
\end{abstract}

Keywords: Myofascial Trigger Point Syndrome (MTPS), Pain, Age, Sex, Teacher 


\section{MIRACLE JOURNAL}

https://ojs.unhaj.ac.id/index.php/mj

\section{Pendahuluan}

Dalam Undang- Undang Nomor 14 Tahun 2005 tentang Guru, salah satu hak guru adalah memperoleh perlindungan keselamatan dan kesehatan kerja mencakup perlindungan terhadap resiko gangguan keamanan kerja, kecelakaan kerja, kebakaran pada waktu kerja, bencana alam, kesehatan lingkungan kerja, dan/atau resiko lain.

Keluhan muskuloskeletal adalah keluhan pada bagian-bagian otot skeletal yang dirasakan oleh seorang dimulai dari keluhan sangat ringan sampai sangat sakit. Apabila otot menerima beban statis secara berulang dan dalam waktu yang lama, akan dapat menyebabkan keluhan berupa kerusakan pada sendi, ligamen dan tendon. Keluhan otot skeletal pada umumnya terjadi karena kontraksi otot yang berlebihan akibat pemberian beban kerja yang terlalu berat dengan durasi pembebanan yang panjang. Sebaliknya, keluhan otot memungkinkan tidak terjadi apabila

kontraksi otot hanya berkisar antara $15-20 \%$ dari kekuatan otot maksimum. Ujung dari permasalahan muskuloskeletal yang sangat mengganggu seorang individu adalah timbulnya nyeri dengan segala deviasinya. Kontraktur mungkin.

Umur seseorang berbanding lurus dengan kapasitas fisik sampai batas tertentu dan mencapai puncaknya pada umur 25 tahun.Pada umur 50-60 tahun kekuatan otot menurun sebesar 25\%, kemampuan sensoris-motoris menurun sebanyak $60 \%$. Selanjutnya kemampuan kerja fisik seseorang yang berumur $>60$ tahun tinggal mencapai 50\% dari umur orang yang berumur 25 tahun, bertambahnya umur akan diikuti penurunan VO2 max, tajam penglihatan, pendengaran, kecepatan membedakan sesuatu, membuat keputusan dan kemampuan mengingat jangka pendek (Tarwaka, 2015).Nyeri muskuloskeletal sangat mengganggu kenyamanan dan produktivitas seseorang yang ditandai timbulnya spasme pada otot yang mengalami kelelahan, nyeri otot pada saat dan setelah aktivitas, kontraktur dan rasa kesemutan. Keluhan yang biasa terjadi pada pekerja sebagai guru adalah seperti nyeri bahu, nyeri leher, dan nyeri pinggang. Nyeri leher yang biasa terjadi berupa Myofascial Triggers Point Syndrome (MTPS) pada otot upper trapezius, dimana merupakan bagian dari Musculoskeletal Disorders (MSDS) yang banyak dialami pekerja (Hanten, dkk, 2000). MTPS sendiri adalah sebuah sindrom yang muncul akibat teraktivasinya sebuah atau beberapa trigger point dalam serabut otot (Edwards,2006). Dengan demikian pengaruh umur harus selalu dijadikan pertimbangan dalam memberikan pekerjaan pada seseorang ( Tarwaka, 2015).

Kondisi guru di SMP Swasta Ar Rahman Medan hampir sama dengan keadaan guru lain, hal ini mendasari penulis melakukan penelitian lebih lanjut mengenai proporsi dan kondisi MTPS khususnya daerah leher dan bahu. Dari pengamatan peneliti, cara duduk guru masih tidak sesuai dengan ergonomic tubuh secara terus menerus sehinngga menimbulkan stress pada otot akibat akitivitas sehari- hari sebagai seorang pengajar.

Dari hasil survei dan wawancara yang dilakukan peneliti terhadap kepala sekolah dan beberapa guru di SMP Ar Rahman Medan, menemukan usia guru- guru tersebut adalah 30 sampai 50 tahun yang mengaku mengalami nyeri dan kaku pada bagian otot sehingga merasa tidak nyaman dalam beraktivitas mengakar di sekolah 
Tujuan penelitian ini untuk mengetahu apakah ada hubungan jens kelamin dan umur terhadap(MTPS) pada guru SMP Ar Rahman Medan.

\section{Metode}

Penelitian ini adalah observasi dengan desain penelitian cross sectional yaitu peneliti mencari pengaruh antara variabel independen (faktor risiko) dengan variabel dependen (efek) dengan melakukan observasi sekaligus pada saat yang sama (Nursalam, 2008). Dalam penelitian ini data seluruh populasi dijadikan sampel yaitu para guru SMP Ar rahman yang berjumlah 32 orang.Sumber data didapat berdasarkan hasil kuesioner kepada responden. Analisis menggunakan uji Chi Square dengan $\alpha=0,05$. Namun apabila chi square jika tidak bisa digunakan atau sampel dibawah 20, nilai E-nya kurang dari 5 dan lebih di $20 \%$ total selnya, maka uji yang digunakan adalah uji fisher exsact (Myrnawati, 2016).

\section{Hasil dan Pembahasan}

\section{Karakteristik Guru}

Tabel 1. Distribusi Frekuensi Umur Guru di SMP AR Rahman Medan

\begin{tabular}{clcc}
\hline No & Umur & Frekuensi & \% \\
\hline 1 & $>35$ Tahun & 19 & 59,4 \\
2 & $\leq 35$ Tahun & 13 & 40,6 \\
\hline \multicolumn{2}{l}{ Total } & $\mathbf{3 2}$ & $\mathbf{1 0 0}$ \\
\hline
\end{tabular}

Tabel 1 menunjukkan bahwa usia responden mayoritas usia >35 tahun sebanyak 19 orang $(59,4 \%)$.

\section{Jenis Kelamin}

Tabel 2. Distribusi Frekuensi Jenis Kelamin Guru di SMP AR Rahman Medan

\begin{tabular}{clcc}
\hline No & Jenis Kelamin & Frekuensi & \% \\
\hline 1 & Laki -laki & 11 & 34.4 \\
2 & Perempuan & 21 & 65.6 \\
\hline & Total & 32 & 100 \\
\hline
\end{tabular}

Tabel 2 menunjukkan bahwa jenis kelamin guru mayoritas perempuan sebanyak 21 orang $(65,6 \%)$. 


\section{Analisis Bivariat}

Analisa bivariat dilakukan untuk melihat pengaruh antara faktor independen dengan faktor dependen.Variabel independen adalah Umur dan Jenis Kelamin dengan variabel dependen yaitu Keluhan Myofascial Trigger Point Syndrome (MTPS).

\section{Hubungan Umur Dengan MTPS}

Tabel 3. Tabulasi Silang Hubungan Umur Dengan Miofascial Trigger Point Syndrome di SMP Ar Rahman Medan

\begin{tabular}{|c|c|c|c|c|c|c|c|}
\hline \multirow{3}{*}{ Umur } & \multicolumn{4}{|c|}{$\begin{array}{c}\text { Miofascial Trigger Point } \\
\text { Syndrome }\end{array}$} & \multirow{2}{*}{\multicolumn{2}{|c|}{ Total }} & \multirow{3}{*}{$\begin{array}{c}p \\
\text { value }\end{array}$} \\
\hline & \multicolumn{2}{|c|}{ Nyeri Sedang } & \multicolumn{2}{|c|}{ Nyeri Ringan } & & & \\
\hline & $\mathrm{N}$ & $\%$ & $\mathbf{N}$ & $\%$ & $\mathbf{N}$ & $\%$ & \\
\hline$>35$ Tahun & 17 & 89,5 & 2 & 10,5 & 19 & $\overline{59,4}$ & \multirow{3}{*}{0,005} \\
\hline$\leq 35$ Tahun & 5 & 38,5 & 8 & 61,5 & 13 & 40,6 & \\
\hline Total & 22 & 68,8 & 10 & 31,3 & 32 & 100 & \\
\hline
\end{tabular}

Tabel 3 menunjukkan bahwa dari 19 orang guru yang berusia $>35$ tahun terdapat 17 orang $(89,5 \%)$ yang mengalami miofascial trigger point syndrome dengannyeri sedang dan 2 orang (10,5\%) yang mengalami miofascial trigger point syndrome dengannyeri ringan. Sedangkan dari 13 orang guru yang berusia $\leq 35$ tahun terdapat 5 orang $(38,5 \%)$ yang mengalami miofascial trigger point syndrome dengannyeri sedang dan 8 orang $(61,5 \%)$ yang mengalami miofascial trigger point syndrome dengannyeri ringan. Hasil uji chi square menunjukkan bahwa terdapat hubungan umur dengan Miofascial Trigger Point Syndrome pada guru $(\mathrm{p}=0,005)$.

Seseorang yang selalu aktifsepanjang umurnya cenderung lebih dapat mempertahankan massa otot,kekuatan otot dan koordinasi dibanding dengan mereka dengan polahidupnya santai. Pada kelompok usia pertengahan, penyebab nyeri leherumumnya bersumber dari myofasial trigger point syndrome dan post traumaticpain. Pada kelompok pasien di pusat komunitas nyeri medikal, ditemukan oleh seorang neurologi bahwa dari 96 pasien 93\% diantaranya mengalami nyeri yang diakibatkan oleh MTPS (Hardjono, 2012). Dengan demikian pengaruh umur harus selalu dijadikan pertimbangan dalam memberikan pekerjaan pada seseorang (Tarwaka, 2015).

Menurut asumsi peneliti yang ditemukan pada guru SMP Ar- Rahman Medan bahwa semakin bertambahnya umur seseorang pada usia dewasa akan dikuti dengan kerusakan jaringan-jaringan tubuh yang menyebabkan penurunan kemampuan fisik yang terjadi yaitu penurunan pada kekuatan otot punggung yang berpengaruh pada aktivitas. Oleh karena itu penurunan kemampuan melakukan aktivitas dan kemampuan kerja menjadi menurun disebabkan oleh penurunan fungsi fisiologis, neurologis, dan kemampuan fisik terjadi sesudah umur antara 30 sampai 40 tahun dengan irama yang berbeda untuk setiap orang.

Berdasarkan penelitian yang dilakukan Sapti (2018), bahwa pada usia dewasa khususnya usia > 30 tahun akan mengalami beberapa penurunan fisiologi, salah satunya adalah penurunan pada sistem muskuloskeletal, adanya perubahan pada tulang,. Perubahan- perubahan yang timbul pada systemotot lebih disebabkan oleh disuse (Widodo, 2011).Saat bekerja membutuhkan peranyang 
membutuhkan peran yang sangat besar dari otot-otot vertebra dan otot- ototleher yang mempunyai peran yang cukup besar dalam mempertahankanposisi leher. Biasanya terjadi pada usia 30 sampai 50 tahun dan lebih banyakpada wanita dibanding laki-laki (Fatmawati,2013).

\section{Hubungan Jenis Kelamin Dengan MTPS}

Tabel 4.Tabulasi Silang Hubungan Jenis Kelamin Dengan Miofascial Trigger Point Syndrome di SMP Ar Rahman Medan

\begin{tabular}{|c|c|c|c|c|c|c|c|}
\hline \multirow{3}{*}{ Jenis Kelamin } & \multicolumn{4}{|c|}{$\begin{array}{c}\text { Miofascial Trigger Point } \\
\text { Syndrome }\end{array}$} & \multirow{2}{*}{\multicolumn{2}{|c|}{ Total }} & \multirow{3}{*}{$\begin{array}{c}p \\
\text { value }\end{array}$} \\
\hline & \multicolumn{2}{|c|}{ Nyeri Sedang } & \multicolumn{2}{|c|}{ Nyeri Ringan } & & & \\
\hline & $\mathrm{n}$ & $\%$ & $\mathbf{N}$ & $\%$ & $\mathbf{N}$ & $\%$ & \\
\hline Perempuan & 13 & 61,9 & 8 & 38,1 & 21 & 100 & \multirow{3}{*}{0,425} \\
\hline Laki-laki & 9 & 81,8 & 2 & 18,2 & 11 & 100 & \\
\hline Total & 22 & 68,8 & 10 & 31,3 & 32 & 100 & \\
\hline
\end{tabular}

Tabel 4menunjukkan bahwa dari 21 orang guru yang berjenis kelamin perempuan terdapat 13 orang $(61,9 \%)$ yang mengalami miofascial trigger point syndrome dengannyeri sedang dan 8 orang $(38,1 \%)$ yang mengalami miofascial trigger point syndrome dengannyeri ringan. Sedangkan dari 11 orang guru yang berjenis kelamin laki-laki terdapat 9 orang $(81,8 \%)$ yang mengalami miofascial trigger point syndrome dengannyeri sedang dan 2 orang $(18,2 \%)$ guru yang mengalami miofascial trigger point syndrome dengannyeri ringan. Hasil uji chi square menunjukkan bahwa tidak terdapat hubungan jenis kelamin dengan miofascial trigger point syndrome pada guru $(\mathrm{p}=0,425)$.

Hasil penelitian ini terdapat bahwa tidak adanya hubungan jenis kelamin dengan MTPS pada guru SMP Ar- Rahman Medan berdasarkan hasil uji analisis bivariat yang didapatkan hasil nilai $\mathrm{p}=0,425$ atau nilai $\mathrm{p}>0,05$.

\section{Kesimpulan}

Berdasarkan hasil penelitian mengenai hubungan umur dan jenis kelamin terhadap Myofascial Trigger Point Syndrome (MTPS) maka didapatkan hasil kesimpulan sebagai berikut:

1. Ditemukan adanya hubungan umur dengan MTPS pada guru SMP Ar- Rahman Medan berdasarkan hasil uji analisis bivariat yang didapatkan hasil nilai $\mathrm{p}=0,005$ atau nilai $\mathrm{p}<0,05$.

2. Tidak adanya hubungan jenis kelamin denganMTPS pada guru SMP Ar- Rahman Medan berdasarkan hasil uji analisis bivariat yang didapatkan hasil nilai $\mathrm{p}=0,425$ atau nilai $\mathrm{p}>0,05$. 


\section{Referensi}

Anggriani, A.Aini, Sulaiman, 2020. Efektivitas Latiahn Range of Motion Pada Pasien Stroke Di Rumah Sakit Siti Hajar. Journal of Healthcare Technology and Medicine, 6(2): 678-684. http://www.jurnal.uui.ac.id/index.php/JHTM/article/view/974

Edwards J. 2006. The Importance of Postural habits in perpetuating Myofascial Trigger Point Pain, Acupunctur med, The journal of manual and manipulative therapy. Abstract.

Fatmawati, F. 2013. Penurunan Nyeri dan Disabilitas dengan Integrated Neuromuscular Inhibition Techniques (INIT) dan Massage Eflurage pada Myofascial Trigger Point Syndrome Otot Trapesius Bagian Atas.Sport and fitness journal. Bali: Universitas Udayana.

Hardjono dan Ervina, A. 2012.Pengaruh Penambahan

Contract Relax Streching pada Intervensi Interferensial Current dan Ultrasound Terhadap Pengurangan Nyeri Pada Syndroma Myofascial Otot Supraspinatus.Jakarta : Universitas Esa Unggul

Myrnawati. 2016. Metodologi Penelitian Untuk Pemula. Jakarta: FIP Press.

Sapti A. 2018. Perkembangan Usia Mempengaruhi Kekuatan Otot Punggung Pada Orang Dewasa Usia 40- 60 Tahun. Abstrak.

Sulaiman, Anggriani, 2018.PkM Pemanfaatan Posyandu Lansia di Desa Sukaraya Kecamatan Pancurbatu Tahun 2017. Jurnal Amaliah, 2 (1): 48-51. https://jurnal1p2m.umnaw.ac.id/index.php/AJPKM/article/view/109

Sulaiman, Anggriani, 2018. Efek Postur Tubuh Terhadap Keseimbangan Lanjut Usia DI Desa Suka Raya Kecamatan Pancur Batu. Jumantik (Jurnal Ilmiah Penelitian Kesehatan), 3(2): 127-140. http://jurnal.uinsu.ac.id/index.php/kesmas/article/view/2875

Sulaiman, Anggriani, 2018. PkM Pemanfaatan Posyandu Lansia di Desa Sukaraya Kecamatan Pancurbatu Tahun 2017. Jurnal Amaliah 2 (1): 48-51. https://jurnallp2m.umnaw.ac.id/index.php/AJPKM/article/view/109

Tarwaka, Bakri A, Sudiajeng L. 2004. Ergonomi Untuk Kesehatan dan Keselamatan Kerja dan Produktivitas. Surakarta: UNIBA Press.

Wardhana AW. 2008. Pengaruh Sustained Stretching Dan Koreksi Postur Terhadap Frekuensi Kekambuhan Laten Myofascial Trigger Point Syndrom Trapezius Descenden. Skripsi. Surakarta: Universitas Muhammadiyah Surakarta.

Widodo A. 2011. Penambahan Ischemic Pressure, Sustained Stretching, dan Koreksi Posture bermanfaat pada intevensi kasus myofascial trigger point syndrome otot trapezius bagian atas.Thesis. Denpasar: Universitas Udayana. 